THE POLITICS OF INNOVATION: REALIZING THE VALUE OF INTRAPRENEURS

Ken Dovey and Bruce McCabe 


\title{
THE POLITICS OF INNOVATION: REALIZING THE VALUE OF INTRAPRENEURS
}

\begin{abstract}
This paper offers three cases, from very different industries, where an organization failed to realize the value of the talent that was recruited at significant cost to lead an attempt at innovation. In each case, the recruited talent was forced into an intrapreneurial role - one in which they had to operate below the management radar - in order to attempt to progress the project for which they were employed. Furthermore, in each case, senior management at the company failed to scrutinize its management practices with respect to the constraints they unwittingly imposed upon the newly recruited person. Through its analysis of the reasons for each of these failures, the paper highlights the dynamics of effective talent management in the knowledge era, and points to alternative leadership practices through which to realize the value offered by talented staff recruited specifically to lead an organization's strategic intent to innovate.
\end{abstract}

Key Words: Intrapreneurship; innovation; talent management; business leadership; organizational learning; intangible capital resources.

\section{Introduction}

In spite of its strategic value, innovation is notoriously difficult to realize in many organizations. The politics of converting a creative idea into a new product, service, or practice are complex and exacerbated by myriad personal, cultural and organizational issues. It is thus not surprising that in many organizations the rhetoric of innovation substitutes for its practice.

In their attempt to innovate, businesses usually recruit talented people with the skills to support their new strategic intent. In many cases, however, once employed these highly-paid people are left to flounder in a sea of 'business-as-usual' practices, procedures and policies that act as unforeseen inhibitors of the requisite business transformation. This usually results in the failure of the business' attempt to innovate, and in the premature departure of the talented person whose value proposition to the business (the very value that the business was seeking in recruiting the individual) has been diluted by a combination of inappropriate business practices and complacent leadership. Forced to work below the organizational 'radar' and operate as intrapreneurs in order to achieve the outcomes for which they were employed, these individuals have to become skilled, very quickly, at navigating the political processes through which their creative ideas must pass in order to realize the intended value for the organization. Most are unable to develop these skills in time and, frustrated and exhausted, leave the organization relatively soon after taking on the role. 
This paper explores the experiences of three talented individuals who were employed to oversee radical changes to the business model of the specific organizations that recruited each of them. The process, however, constrained the exercising of their unique skills and exhausted their energy resources, leading to all three resigning within two years of taking on the role. In our analysis we explore each case from two perspectives: (i) how, once forced into an intrapreneurial role, all three individuals failed to sustain the sources of energy and creativity required to navigate the political challenges to innovation; and (ii) how the leadership of each of these businesses failed to leverage the 'talent' that they had acquired specifically for their attempt at innovation and, more importantly, failed to learn from this experience.

\section{Innovation and the Concept of Intrapreneurship}

Moultrie and Young (2009, p. 300) argue that 'creativity is often defined as the production of ideas which are both novel and applicable to an identified opportunity'. From this perspective, ideas can be viewed as a source of conceptual capital - a set of intangible capital resources upon which innovation feeds (Dovey and Mooney 2012) - and innovation seen as the realization of relevant and promising ideas. However, because human endeavour is characterized by competing interests and, thus, ideas are likely to be viewed through the lens of self- and sectarian-interests (Simonton, 1984), such realization is very difficult to achieve in practice (Barsh, 2008; Barsh et al, 2008; Dovey \& Fenech, 2007). Slowly, however, published research is showing that it takes a courageous and enlightened form of covert leadership - that performed by self-appointed champions of ideas or intrapreneurs - to ensure the realization of ideas that, while being unwelcome to some, are critical to the future of the organization (Antoncic and Hisrich, 2003; Hamel, 2000; Abetti, 1997; Augsdorfer, 1994; Pinchot, 1985). Through this view, intrapreneurial practices are seen as astute ways of stewarding creative ideas through the hurly-burly competitive politics of enterprise life (politics that would otherwise crush them). Most important among these practices is the nurturing of an idea until sufficient management support has been built and the requisite resources for its realization have been mobilized.

In attempting to define the term, de Jong and Wennekers (2008, p.4) state that existing definitions of intrapreneurship share three features: (i) intrapreneurs are proactive individuals with a strong desire for action. They are 'self-starters' who do not have to be asked to take the initiative; (ii) their proactive behaviour is focused on the pursuit of an opportunity without regard to the resources they currently control; (iii) intrapreneurs often pursue something that in some sense is 'new' or 'innovative'; that is, intrapreneurial behaviours and actions deviate from the status quo.

In summary, the set of signature practices of intrapreneurs includes the ability to recognize and champion the right ideas; to build a coalition of support (initially below the management radar) that will facilitate the realization of such ideas; and to ensure the appropriate allocation of resources to the realization processes. However, as a potential disruptor of the status quo, they 
need to be skilled in the politics of change in order to survive and to contribute to the longevity of the organization.

While the three individuals covered in this paper cannot be classified as experienced intrapreneurs, they all share some features of the intrapreneurial mind-set. In particular, their energy and creativity is derived from constant exposure to intellectual challenge; learning interesting and meaningful things drives their commitment to task; and continuous evidence of progress towards the achievement of designated outcomes sustains their motivation. Furthermore, they all have an unusual generosity of spirit and are motivated by 'making a difference' in the world in some way.

\section{The Research Approach: The Phenomenological Interview}

Early in 2013, the authors became aware of three individuals who had been tasked to lead an attempt at innovation in separate well-known companies, without success. Given the companies' strategic intent to innovate, and given the quality of the person hired in each case to execute that strategy, these failures intrigued the authors and they sought interviews with each of the three individuals. These interviews, each of which was around one hour long, were recorded and transcribed verbatim. In each case, the interviewee was asked to talk about his experiences at the respective business, with the interviewer probing for greater detail of explication. In this way, the constructs were generated by the interviewees - individuals who had experienced the phenomenon of having been recruited to innovate within a large company - without any contamination of this process through interviewer-generated questions. The analysis of the interviews delivered two sets of themes that recurred across all three interviews: firstly, a set of themes reflecting the antecedents and dynamics of intrapreneurial failure; and, secondly, a set of themes reflecting the inappropriate practices of senior management that underpinned their failure to realize the value offered by the recruited talent. In this way, the paper offers useful insights on the reasons why large organizations fail to innovate in spite of their explicit intent to do so.

The study is located within the interpretivist research paradigm, and utilises a phenomenological methodology. Within this paradigm, the ontological assumption is that organizations are socially constructed and have no objective reality beyond the inter-subjective processes that sustain their 'existence' in the minds of those who engage in the everyday practices that uphold the consensual reality of the organization. The epistemological assumption is that the nature of the knowledge, sought through the interview method, is subjective, and that it is experientially derived and dependant for its articulation upon the interviewee's interpretive, sense-making, and, most importantly, linguistic capabilities.

The intention in each case is to access the privileged knowledge gained by the individual who was employed to lead the organization's attempt at innovation; that is, the person with direct experience of the phenomenon of attempting to innovate within a specific organization. There is no assumption of generalization of these results (as would be expected of positivist research). 
Rather, the three cases offer rich insights into the personal and organizational contexts in which attempts at innovation occur; insights that might provide useful frames of reference for would-be innovators in other organizations.

\section{The Cases}

\section{Case 1: Intrapreneurship in a book retailer}

Alphabooks, a major book retailer, had a strong brand, a national chain of stores, an existing online presence, and was outperforming its nearest competitors. Aware of the new technologydriven threats to the industry, management hired Alan to extend the e-commerce capability by exploring new opportunities and markets for Alphabooks.

When Alan arrived he found the core technology in Alphabooks was barely adequate to support the current business; much of it being ten years old and poorly architected. He decided that the immediate priority was to modernize it but, as soon as he started to articulate the required technology and personnel changes, he began 'hitting brick walls'. The barriers came in two forms: unrealistic expectations over what online technologies should cost; and longstanding expenditure approval policies that were onerous and restrictive. He was being asked to 'make significant changes to the business without spending any money’.

In parallel with the core upgrade work, Alan conceptualized a new service offering - an innovative streamlined self-publishing capability for authors - that supported the CEO's idea of diversification into publishing, and replicated the creative revenue models employed in other forms of e-commerce (e.g. subscription, ad-funded, freemium, sponsorships, etc). The Board signed off on Alan's concept. With hindsight, Alan realized later that, at the time, the directors had little understanding of what they were signing off on. Some months later the technology had been built and the project was launched. To give the project the best chance of success, Alan invested significant time and energy in educating and consulting all the affected stakeholders.

An early challenge came from the Board who demonstrated unrealistic expectations regarding how quickly the service would be successful. Disappointed that revenues had not flowed immediately, soon into the project the directors called for it to be shut down. As Alan put it, 'support began to evaporate a month after sign off'. In his view any assessment of overall success realistically could only be made eighteen months after the launch. At this time the CEO left and a restructure led to Alan reporting directly to the Board. Given the Board's technological naivety and view of technology as a 'money sink', Alan had to continually educate directors on the importance of the new service to the business.

Two years after taking the job, Alan had become frustrated by 'constantly having the same battle and same conversations with the Board'. He had become exhausted by the stakeholder management activities, and he found unpalatable the prospect of 'three years more battling to get 
the service over the line'. He felt he was no longer doing creative and interesting work and worried that this would erode his skills and reduce his employability. He resigned; refusing the alternative roles offered to him in an effort to retain his services at Alphabooks.

\section{Case 2: Intrapreneurship in an online media company}

Bill was hired into the strategy group of Betamedia, a multinational online media conglomerate that owned a diverse portfolio of 'stand-alone' online properties. Its primary source of revenue was online advertising in multiple, diverse forms and across many different types of content. A secondary source of revenue was subscriptions. Bill's role was to drive innovation in the business but, within six months of taking the role, he felt frustrated. He found he was the 'go to' person on innovation but enjoyed no direct authority and no resources to actually implement any ideas. He described his situation as 'wearing a paper crown'.

Together with the Chief Operating Officer, Bill decided to conduct a strategic review of all the commercial aspects of the business, including pricing, sales methods and inventory management. Out of this came the realization that Facebook and Google were taking the market in a new direction that threatened future revenues. Bill described Betamedia as ‘hurtling towards pain'. He was unsuccessful in convincing senior management of the scale of the threat so he changed tactics and began preparing a business case and program of change based on a detailed analysis of online content, relevance and audience value. He came up with an opportunity to greatly improve the management of audience information engagement and retention. Hitherto each web property had pursued its strategy independently but Bill's proposed approach required people to change their 'vertical' product mindset to one that took advantage of 'horizontal' interconnections, and included a framework for ensuring that new product developments incorporated an integrated approach to audience engagement from the outset.

The proposal was tabled with a detailed business case and a four-year capital program. It encountered resistance from management, principally because it was expensive and did not return short-term revenues. At this time a new CEO arrived whom Bill described as 'one of the best people I've worked with.' She quickly became an ally and the proposal and capital program were approved. Resistance from peers was immediate, in particular to ceding direct control of resources to a shared resource pool, and to the notion that other products must be taken into consideration when changing a product or justifying an investment. Bill appealed to the CEO who mandated that all products were to be built as per Bill's proposal. To his surprise, the CEO's edict was 'roundly ignored'. Trying a new tactic, Bill implemented several pilots to demonstrate the benefits of his proposal, to no avail. After persisting for several months he conceded defeat and left Betamedia.

Case 3: Intrapreneurship in a professional services company

After running his own consulting business, Peter landed a directorship at a multinational professional services firm, ServiceCo. Peter's motivation was to use the resources and brand of 
ServiceCo to build a new and innovative services practice. However, the Partner hiring Peter needed to produce provocative 'thought leadership' on behalf of the firm and asked Peter to address this issue before building the new innovation practice.

Peter brought with him a series of engagements already won by his consultancy. He immediately encountered ServiceCo's extensive risk management procedures. More than a day and a half of administrative overhead was consumed before undertaking the first small assignment. Attempting to draw personnel from ServiceCo's talent pool for a larger engagement, Peter could not access the skills he needed to undertake the strategic work he was bringing in. With his reputation on the line and having been refused permission to hire his own specialist personnel, Peter completed the job himself.

Peter learned that he was operating in a competitive environment in which personal interests often trumped the collective interest, and where senior management secured the best staff for their own work. His investments in developing staff were wasted when, once trained, they were poached for other projects.

After establishing a systemic approach to 'thought leadership', Peter was given permission to employ someone to manage it under his mentorship. He was now able to build the new practice and began with two creative online marketing initiatives. Once again he ran into ServiceCo's rigid corporate guidelines and risk management procedures. After a considerable investment of time and energy spanning multiple layers of management and many months, he was allowed to proceed with only one initiative, and with strictly imposed controls that neutralized most of its value.

Without the benefit of the marketing initiatives, Peter set about growing his practice by engaging with prospects directly. He won a series of small assignments, using each as a reference to win the next. As each assignment succeeded and began to grow in scale and value, momentum was built and, with revenue flow, permission to hire was granted. He recruited two talented individuals from outside ServiceCo and began building a viable service offering that enabled clients to introduce new practices around critical business issues. His successes brought unwanted attention and Peter was forced to expend time and energy defending his practice as senior Partners sought access to his staff. Then one senior Partner attempted to appropriate his practice and subsume it into one led by her protégé. Peter's threat to resign if the executive committee allowed the appropriation to proceed, led to the proposal being quietly dropped. Then, out of the blue, Peter's work was selected for a risk compliance audit. The work passed but the fear the process generated in those around him, particularly his own boss, made a lasting impression on Peter. He concluded that the risk management regime was strangling ServiceCo's ability to innovate.

With the innovation practice gathering momentum, Peter's personal energy resources were being depleted. Most of the daily work involved administrative compliance procedures and seeking 
internal permissions. In an attempt at personal renewal, he sacrificed part of his salary to invest time in accessing knowledge-rich, creative social networks. The final straw came when he was told that it would take two years to approve the innovation practice as a product that could be accessed by ServiceCo's international affiliates. He realised that his next two years would be taken up with this approval process, other administrative procedures, and internal battles to change the company's product approval procedures. Having no appetite for work that was not intellectually rewarding, and with his energy resources expended, he announced his resignation. One year after Peter's departure, the innovation practice ceased to operate as a stand-alone practice.

\section{Analysis of Results:}

\section{The antecedents and dynamics of intrapreneurial failure}

Several themes, that reflect how aspects of the intrapreneurs' behaviour contributed to the failed initiatives, are apparent across the interview data:

1. Failure to scrutinise the enterprise in its entirety (its structure, culture, current state of technology, governance, resourcing policies/practices, etc.) before accepting the role.

A strong theme in all three cases was the lack of initial understanding by the intrapreneurs of aspects of the business that would constrain their ability to achieve their objectives. Understanding came as a series of unpleasant surprises after they had commenced their new roles. Alan, for example, on entering the business was shocked by the inadequacies of the existing technology at Alphabooks:

The first thing I noticed when I got into this environment was that 'business as usual' was shockingly bad from a digital perspective - really, really bad. The worst technology environment I’ve ever walked into.

This was followed by further shocks as he realized the scale of the challenges posed by an outmoded management culture and, in particular, a Board that was woefully naïve with respect to the task that he had been employed to fulfill:

There was no real concept of what digital content is, was, or could be ... There was this sense ... that change ... if it involves technology should be really cheap ... there was this really interesting moment, four or five months in, where I had a cap-ex request to the Board for fifty thousand dollars and one of the Board members said, 'Well, where does this get us in relation to Amazon?'.

Similarly at Betamedia, Bill was surprised by the unexpected resistance from above to his proposal:

There was a huge amount of resistance because it was an expensive change that didn’t necessarily yield direct revenues in the short term. 
He was later surprised by resistance from peers to cross-silo collaboration and resource sharing:

It's when you actually start to get people to try and use it you get real resistance ... you are shifting from a vertical, with absolute resource assigned to it, to (a horizontal) where there is a shared pool of resources, and that's not popular.

At ServiceCo, Peter was astounded by the breadth and power of the risk management regime:

This was the first time I'd heard of (a random risk audit) ... which was already a problem ... So I'm experiencing it and ... I'm just appalled by the way it's handled ... it felt like someone had directly questioned my integrity.

This was followed by the discovery that the skills he needed were not available from the existing talent pool; and the progressive realization that he was battling a highly adversarial culture when it came to securing talent:

The resources available weren't suited to what I was trying to do ... I went back and said, 'We do not have the right people. You want me to do this, and I want to do it, but to do this we need the right people.' ... I never got permission to hire somebody ahead of the curve ... So I was bootstrapping this thing [and] doing it on a shoestring.

While there are limits to what can be discovered in advance, none of these three intrapreneurs adequately explored the nature of the business contexts and, in particular, the assumptions of senior leadership before accepting the role. While Alan's lament that, 'sometimes you need to go on a journey before you realise how bad something is', is to some extent valid, in all three cases the respective intrapreneurs were adamant that they would ask tougher questions before accepting their next role. Alan, for example, would:

ask a lot more questions around the condition of the technology infrastructure and the Board's policy on capital expenditure.

While Peter had asked about resources before joining ServiceCo, in hindsight he realized he should have probed the answers he had received, more effectively:

I had asked repeatedly, 'how many staff can I get?' And 'what budget do I get?' ... but they would say 'there's a labour pool'.

2. Failure to negotiate decision-making power and access to resources before accepting the role:

The best opportunity to negotiate an adequate power base and access to appropriate resources is before taking on the role. All three of these intrapreneurs failed to do so. As Alan puts it:

I thought I had (a power base) - I had full buy-in from the CEO and complete P\&L responsibility for my unit - but ... when it (came) to committing capital to 
the change, and therefore properly enabling the change, that's really where (I) hit the road blocks.

Bill succinctly expresses his dismay when realising that he had taken on the role at Betamedia, without any capacity to effect change:

It was like wearing a paper crown ... (I had) no authority and resources to do anything ... (I) spent a lot of time talking to people and getting frustrated.

In each case, only after accepting the role did the intrapreneur become aware of his powerlessness. Furthermore, the longer the intrapreneur functioned within the system, the less able was he to leverage greater negotiation power. As with the need to ask tougher questions initially, both Alan and Peter felt that they should have 'taken a stand' on key issues early in their tenure:

I would dig my heels in about addressing the core and fundamental problems within the business, a lot earlier (Alan).

In hindsight I would have pushed harder, earlier for the people ... within the first few weeks ... If I had understood the power that I had, I would have wielded it much earlier (Peter).

Peter also claims that he would have negotiated different metrics - change metrics - upon which to evaluate his performance, at least during the development of the new product.

\section{Failure to renew personal energy:}

All three intrapreneurs failed to sustain their personal energy levels. There were multiple dimensions to this phenomenon. First, they exhibited the selflessness and total commitment to an outcome that is characteristic of intrapreneurs; making personal sacrifices to achieve an organizational outcome that mattered to them. The nature of their motives is well described by Bill:

I genuinely get excited about the opportunity to improve ... I don't mind that the idea can be changed or even reversed, as long as the positive outcome can be achieved. I don't feel like it has to be my idea. I feel like I'd like to bring everyone on that journey towards an outcome.

Peter shares this outlook:

I went into [ServiceCo] totally committed, mentally, to giving it everything ... that it would get everything out of me; and to do the best possible job because I wanted the legacy of having done this. 
Such motives were backed up by action. Whenever Peter, for example, encountered a new obstacle, he did not hesitate in taking it on himself. Each time he bought a short-term gain in progress or resources but with a long-term personal cost:

So then I did something that every management text says you should never do. It was so important for me to show them [how it should be done], I went and did almost all the work myself. It almost killed me ... but [it] served its purpose ...

Second, all these intrapreneurs underestimated the scale of the tasks they were taking on. In Alan's case he took upon himself the responsibility for engagement with every stakeholder group across Alphabooks:

Spending time with the buying team, the marketing team, the technology team, the merchandising team, the store staff and ... being available to answer the questions that they have ... making yourself available in a consultative way rather than a directive way.

Third, the intrapreneurs were not sufficiently self-aware: overestimating their capacity to address obstacles day after day for a protracted period, and taking insufficient care to engage regularly in endeavours that renewed their motivation. All three were clear, however, about how they would approach their next challenge. Bill said, for example:

What I hadn't anticipated ... was that it is exhausting ... you are constantly supporting [the change] and pushing for it at a very active, day to day level. (I realized) that I don't have limitless energy, and that, at the start, in selling the change, (it is important ) to ... bring in more formal structure and commitment from a business perspective, (with respect) to sharing some of that burden.

Alan failed to understand the limits of his personal energy when, over and above his other responsibilities, he took on the onerous and frustrating task of attempting to persuade the Board on key issues:

My reasons for leaving were frustration with (the Board's) calcified approach to how a business needed to be run. You're constantly having the same battle (and) conversation with the Board ... you're constantly trying to convince them that a series of bad decisions over the last decade cannot be reversed in a short period of time with no money.

Fourth, the primary source of inspiration for all three intrapreneurs is making a difference. Evidence of such was elusive in all three cases. Peter expresses this cogently:

I wanted to have an impact. I wanted to build a lasting practice that when I left ... (I would) know (was my) legacy. I was quite happy to walk away having worked myself out of a job ... (but) I could see that getting further away rather than coming closer. 


\section{Failure to renew the sources of their creativity:}

The value proposition to which intrapreneurs best respond includes opportunities to express their creativity and to learn interesting things through challenging work. In all three cases, the failure to renew the sources of their creativity and intellectual interest led to the decision to resign. Alan sums up the situation that led to his departure from the role:

I don't feel creative any more. Nothing interesting is coming out of my head, I'm not doing any interesting work, and I feel like if I spend the next three years battling to get work over the line ... I (will) end up out in the marketplace (with) my potentially unique skills (having been) eroded.

Peter recognised the problem at a late stage and tried unsuccessfully to address it:

You have to sustain yourself ... the tactics that I was using were not working ... I hit a cliff and thought, 'Now there's nothing left for me intellectually'.

He laments the lack of regular feedback from his boss - of acknowledgement and appreciation of the value of his contribution - and recognition of the 'differentness' of his role:

when you're embarking on a mission to change a culture and you're an alien - or a stranger in a strange land sort of thing - and you're doing something very different ... you need to believe that what you're doing is appreciated and that it’s going somewhere.

Within the individualistically competitive cultures characteristic of most modern organizations, such needs are unlikely to be met. These are issues with which successful intrapreneurs have come to terms; in particular, that of coping with their 'marginality' within the firm. However, it is this same marginality (in association with their capabilities), that facilitates their creative contribution to the organization; their capacity to see what others cannot see and to invent ways around the conventional barriers that constrain innovation within large organizations. From a human perspective, though, to be marginal is to be an outsider, without emotional affiliation. As Peter's case shows, the need to know that you are not alone in your mission/vision, and to be emotionally affirmed by others, is a powerful one

\section{Overestimating the influence of a senior sponsor:}

All three intrapreneurs pursued strategies of securing the support of senior sponsors to help achieve their objectives. Alan reported to the CEO, switching his attention to the Chairman of the Board when the CEO resigned. However, the Chairman's poor grasp of digital developments prevented him from decisively backing Alan's recommendations. Similarly, Bill first secured the COO's sponsorship at Betamedia, and then that of the CEO. He went directly to the CEO to get 
backing to overcome resistance; won it, and was shocked to discover it didn't make any difference:

[the CEO was] one of the best people I've ever worked with. Very good at asking the right questions ... got it straight away and said "this is how we are going to build products” ... and was roundly ignored ... cultural resistance is really quite formidable.

Peter came into ServiceCo confident he had the backing of a powerful Partner but quickly learned this was insufficient to secure the resources he needed at ServiceCo:

When I came in I had [Partner] working with me, pulling in the same direction. I assumed that the CEO and all the others around him were also pulling in that direction ... The reality was it was only [Partner] and even though the CEO gave me the right words, emotionally he wasn't committed.

In all three cases, the intrapreneurs overestimated the power and influence available to them through these sponsors.

\section{The inappropriate practices underpinning management failure to innovate}

Several themes, relating to management failure to realize the potential value that the acquired talent offered the organization, recur across all three sets of interview data:

\section{Absence of talent management practices:}

In each of the three cases, management had, at considerable expense, brought a talented and motivated individual into the organization to help realize an attempt at much-needed innovation. However, once employed in the role, the talented individual was left to flounder in a sea of 'business-as-usual' policies, practices and procedures, and allowed to be buffeted by the competitive politics within each organization. In all cases the talented person was lost to the business, against the wishes of management, within two years of taking on the role.

In a mirror-image of the intrapreneur's incomplete understanding of the business, management failed to comprehend the kind of person they were acquiring in the intrapreneur. In particular, they failed to appreciate the unique motives, needs, and sources of inspiration of these people, and the different value proposition to which such talented individuals respond. They needed to be managed differently if the value that the business had sought in acquiring them was to be realized. Instead these people were subjected to standard regimes, with the investment made in them by the organization, wasted.

At Alphabooks, the Chairman failed to intervene in matters such as the Board's interference in Alan's role, and his reluctance to invest appropriately in the new initiative directly contradicted his choice of Alan to lead the change process. 
At ServiceCo, Peter's boss did not shield him from an environment characterised by aggressive competition for resources and excessive bureaucratic compliance procedures. To him these taken-for-granted business routines had nothing to do with the realization of the outcomes for which he had employed Peter. As a result, Peter's energy was being expended on surmounting internal barriers and, having been denied external opportunities for personal renewal, the sources of his motivation - challenge, making a difference, and learning interesting things - were drying up. As Peter explains:

It's not that they don't want you to succeed but they are quite willing to let you fall into the same systems that will end up killing you, rather than carve out a space for you in all the things that you need.

While Peter communicated his need to access ideas and inspiration through regular interaction with knowledge-rich external social networks in order to constantly renew his creativity, his boss failed to comprehend such a need:

I said, 'You have to think of me as a creative entrepreneur. My brain is a bit different to everyone else - if it's not getting that stimulation, I can feel the life draining out of me'. He said, 'Yes' ... [but] he left it way too long ... even after I gave him clear feedback that it wasn't working ... and that I was burning out, he didn't sufficiently address it.

Peter was an expensive asset and simple steps could have been taken to improve his situation. When he realized that for the following two years his time would be dedicated to the tedious procedures required for product approval - an aspect of his job that could easily have been reassigned to someone else - he made the decision to leave ServiceCo.

\section{Failure to comprehend the leadership requirements of change}

In all three cases, management failed to fulfil their own responsibilities with respect to facilitating the desired change. Rather than creating an aspirational vision, and using their position to inspire the entire workforce to accept shared responsibility for the success of the initiative, they delegated the responsibility for a complex attempt at innovation to a single individual who, though talented, had little power within the organization. In this manner, all three intrapreneurs were left to take on more and more of the burden themselves with little support from above. As Bill describes it:

The danger is that you become the beacon (for change). (Others see you as) the guy that's going to look after the change bit so therefore they don't have to ... 'Oh great, this isn't my responsibility; this is your responsibility.' ... Everyone (should) have a role to play - some roles are bigger than others, absolutely - but everyone (should have) a role.

By failing to empower Bill with decision-making authority and access to resources, Betamedia's leadership neutralized the value that they had 'bought' in giving him the role. The CEO, while 
highly supportive of Bill's initiative, did not go further than issuing an ineffective edict to overcome the resistance he was encountering.

In the case of Alphabooks, the Board members had dismally unrealistic expectations of the speed with which change would occur:

There was impatience, immediately, from the board. So I was saying look it's clear we are learning a hell of a lot in these first few months about how we need to pitch the business and about improvements we need to make [but] there were calls from the board within about a month to shut it down ... The idea that this was a failure after only four to eight weeks was bizarre to me.

Furthermore, the Board failed to grasp the disruptive and cost implications of the strategy through which they were intending to transform the business; as well as the impact of the organizational structure of Alphabooks upon its effective execution:

They really didn't understand ... that getting into ecosystems requires constant innovation and investment. (The Board wanted to) make significant changes to the business without spending any money.

In Peter's case it was quickly established that the existing ServiceCo personnel were incapable of doing the creative work that he was sourcing. Peter needed to hire outside the organization but ServiceCo's policy of 'generate the revenue first and then we'll give you permission to hire', made this impossible.

Another issue was the unwillingness by managers to acknowledge the full extent of the challenges faced by the organization. There seemed to be two reasons for this reluctance: fear of discouraging the intrapreneur from accepting the assignment initially; and fear of supplying the intrapreneur with a justification for requesting additional money or resources. Whatever the reasoning, this misguided approach helped to hasten the departure of the intrapreneur - an outcome that was not in the interests of any of these organizations.

3. Failure to develop the necessary skills and knowledge in the executive team and the Board:

A consistent theme across these cases is the ineffective leadership of these organizations. The ignorance displayed by the management of Alphabooks and Betamedia of fundamental digital shifts impacting their industries - shifts that represent strategic threats to the future survival of their respective organizations - is surprising. In this respect, the composition of the Alphabooks' Board, in particular, was hopelessly inadequate for evaluating the strategic innovations that Alan was proposing:

The lack of understanding and interest in what you'd call the digital economy and consumer behavior ... was a shock. 
In each case, the leadership of the organization failed to comprehend the lack of 'absorptive capacity' amongst its senior members with respect to understanding what it would take for the new venture to succeed. Similarly, none showed any degree of 'intellectual humility' - that is, the ability to recognise the limits of their own knowledge in the domains in which they were attempting to innovate.

\section{Discussion of Results}

The cases highlight the failure of leadership in each organization to leverage the talent that had been recruited for the specific purpose of exploiting new opportunities. In this, they condemned their organizations to the status quo with respect to everyday practices, knowledge bases, and capabilities. On trial, as these cases demonstrate, is the capacity of many business leaders to scrutinize the 'deep structure' of their leadership make-up: the assumptions that underpin decisions and attitudes that often contradict their organization's explicit strategies, and that mask the difference between espoused-intent and intent-manifested-in-practice. Furthermore, the evidence of leadership failure to learn from failure, that these three cases highlight, reflects levels of management complacency and hubris that constrain the development of new knowledge and organizational transformational capabilities. In particular, the lack of absorptive capacity of business leaders - the capacity to comprehend the organizational capabilities necessary to adopt innovation as a competitive strategy (see Lewin et al, 2011) - appears to be at the heart of their failure to learn to innovate through critical self-reflexive practice.

These cases also show that, in spite of management rhetoric about the importance of talent in the 'knowledge era', there is widespread mismanagement of talent. New forms of talent management are required: forms in which business leaders (CEOs and Boards) exhibit appropriate intellectual humility as they partner with the talent they recruit in order to ensure the realization of the potential business value in innovative new products, services and/or practices. Such collaborative practices will prevent scarce organizational resources from being squandered through lost opportunities, and stop individual lives from being damaged by business leaders' failure to understand and manage the social dynamics of innovation.

The interview data suggest several practices that business leaders could adopt to manage talent more appropriately during attempts at innovation. These include:

The establishment of an initial short-term contract of engagement of the targeted individual.

In order to ensure the compatibility of intent and understanding, some form of initial 'consultancy' is optimal prior to the formal engagement of the talented person. During this period, the talented person scrutinises the business from multiple perspectives (structure, culture, governance practices, policies and procedures, existing technology, appetite for risk, etc.) and reaches agreement with the leadership on its strategic intent to innovate; changes to be made to the way the business operates; the empowerment practices required to execute the strategy effectively; and a time-frame for the realization of this 'new value' for the organization. 
Shared 'ownership' of the innovation project.

Once the talented person is employed with the specific responsibility (and decision-making power) to steward the organization through the changes required to realise its strategic intent to innovate, the organizational leadership needs to partner with that talent and provide a 'procedural moratorium' whereby the talented individual is buffered from many of the normal procedures (forces for conformance and standardization) within the organization.

The co-creation of a shared 'vision' for the innovation project.

At the commencement of the project, the leadership team undertakes an organization-wide 'visioning' campaign aimed at educating, inspiring and aligning all stakeholders on the importance of the innovation, and their role in its realization. Included in this campaign is the cocreation of a 'negotiated order' based upon a set of core values, upon which all stakeholders in the project reach consensus, whereby everyday interaction and decision-making within the project is co-governed (see Martincic \& Dovey, 2011).

\section{Checking-in on stakeholder learning and knowledge conversion:}

During the spirals of strategic execution, regular stakeholder forums for critical reflection on the effectiveness of strategic execution are facilitated jointly by the talented person and the organization's leadership team. These sessions also constitute opportunities for the conversion of the Mode-2 tacit knowledge (see Gibbons, 2000), co-created through the strategic action, into more strategically useful explicit knowledge. In this way, 'deep learning' is facilitated (see Argyris \& Schon, 1996) in which assumptions [cultural assumptions (see Schein, 1985) and personal 'mental models' (see Kim, 1993)] are made explicit, debated and, where they are seen as constraining innovation, transformed. In this way, multiple forms of value - personal, professional and organizational - are realized.

Checking-in on mutual value realization within the partnership:

The leadership team periodically 'checks in' with the talented person on whether the value proposition of their role (challenge, new knowledge generation, and evidence of 'making a positive difference') is being realized; and the talented person 'checks in' on whether the 'value' for which s/he was recruited (the creation of innovative new products, services and new organisational capabilities) is being realized by the organization. These serious conversations are scheduled on a regular basis, over-and-above conventional performance reviews.

Renewing the intellectual and emotional resources of the knowledge partners:

Through a series of brief 'sabbaticals', the talented person is funded to seek broader intellectual input into the strategy by attending relevant conferences and engaging knowledge-rich external networks in face-to-face conversation. In this way, the talented person's sources of energy and creative ideas are renewed on a regular basis and the organization becomes the beneficiary of 
broadly-sourced ideas and knowledge. Similarly, the organizational leadership team is funded to renew its knowledge and experiential frames of reference on a regular basis, and is encouraged to scrutinise its composition regularly with respect to relevant diversity of membership and currency of knowledge.

\section{Conclusions}

The analysis of these three cases raises important issues about the politics of innovation. Most importantly these cases show that innovation requires collaboration between organizational leaders and the talented individuals they recruit to drive the innovation processes. Through such collaboration different knowledge bases and competing power interests are reconciled and aligned in new organizational practices. These practices include modes of governance that support constructive critique and feedback, and organization-sponsored initiatives through which key stakeholder knowledge bases are enhanced and expanded continuously. As such practices draw strongly on relationship-based intangible capital resources - resources such as trust - the nurturing of vital stakeholder relationships, and the constructive forms of communication that sustain them, is vital to effective innovation.

Another issue raised by these cases is the need for studies located in alternative research paradigms - such as the interpretivist and constructionist research paradigms - that recognise the political nature of organizational realities. As the bulk of the literature on innovation is located within the positivist research paradigm, the potentially disruptive impact of attempts at innovation upon vested interests and established power bases within organizations, is rarely mentioned. Similarly, there is a need for more research that scrutinizes the impact of mental models (particularly assumptions about 'self', 'others' and 'the way the world works') upon the ability of leaders to steward their organizations through domains in which their previous experience and current knowledge is inadequate. An important goal of such research would be a better understanding of the antecedents of the 'humility' leaders will require in order for them to learn how to collaborate with talented people whose knowledge and experience is more pertinent to the situation. This will be a challenging personal task for many who have been successful in the past in that the first step in learning is the acknowledgement of one's relative ignorance in the new domain.

\section{References}

Abetti, P. (1997) 'Underground innovation in Japan: The development of Toshiba's word processor and laptop computer', Creativity and Innovation Management, Vol. 6, pp. 127-139. Argyris, C. and Schon, D. (1996) Organizational Learning II: Theory, Method and Practice, Reading (MA), Addison-Wesley. 
Augsdorfer, P. (1994) 'The manager as pirate: An inspection of the gentle art of bootlegging', Creativity and Innovation Management, Vol. 3, pp. 91-95.

Antoncic, B. and Hisrich, R. (2003) 'Clarifying the intrapreneurship concept', Journal of Small Business and Enterprise Development, Vol. 10 No.1, pp.7-24.

Barsh, J. (2008) 'Innovative management: A conversation with Gary Hamel and Lowell Bryan', The McKinsey Quarterly, Vol.1, pp. 24-35.

Barsh, J., Capozzi, M. and Davidson, J. (2008) 'Leadership and innovation', The McKinsey Quarterly, Vol. 1, pp. 38-47.

de Jong, J. and Wennekers, S. (2008) Intrapreneurship: Conceptualizing Entrepreneurial Employee Behaviour, Zoetemeer (Netherlands), SCALES, Netherlands Government.

http://www.entrepreneurship-sme.eu/pdf-ez/H200802.pdf (accessed 8th November 2011).

Dovey, K. and Mooney, G. (2012) 'Leadership practices in the generation and deployment of intangible capital resources for innovation', International Journal of Learning and Intellectual Capital, Vol. 9 No. 3, pp. 295-306.

Dovey, K. and Fenech, B. (2007) 'The role of enterprise logic in the failure of organizations to learn and transform’, Management Learning, Vol. 38, pp. 573-590.

Gibbons, M. (2000) 'Mode 2 society and the emergence of context-sensitive science', Science and Public Policy, Vol. 27 No. 3, pp. 159-163.

Hamel, G. (2000) Leading the Revolution, Boston, Harvard Business School Press.

Kim, D. (1993) 'The link between individual and organizational learning', Sloan Management Review, Vol. 35 No. 1, pp. 37-50.

Lewin, A., Massini, S. and Peeters, C. (2011) 'Microfoundations of internal and external absorptive capacity routines’, Organization Science, Vol. 22 No. 1, pp. 81-98.

Martincic, A. and Dovey, K. (2011) 'Action research as a knowledge generating change methodology’, International Journal of Learning and Intellectual Capital, Vol. 8 No. 1, pp. 108122.

Moultrie, J. and Young, A. (2009) 'Exploratory study of organizational creativity in creative organizations', Creativity and Innovation Management, Vol. 18, pp. 299-314.

Pinchot, G. (1985) Intrapreneurship: Why You Don't Have to Leave the Corporation to Become an Entrepreneur, New York, Harper \& Row.

Schein, E. (1985) Organizational Culture and Leadership, San Francisco, Jossey-Bass.

Simonton, D. (1984) Genius, Creativity, and Leadership: Historiometric Inquiries, Cambridge (MA), Harvard University Press. 